\title{
ENERGY DISSIPATION CHARACTERISTICS OF SLAB TYPE BUILDINGS WITH SPECIAL CONNECTORS
}

\author{
Erkan Şenol ${ }^{1}$, Ahmet Anıl Dindar ${ }^{2}$, Ercan Yüksel ${ }^{3}$ and Faruk Karadoğan ${ }^{4}$ \\ ${ }^{1}$ Yildiz Technical University, Department of Civil Engineering \\ Davutpasa, Istanbul, Turkey \\ e-mail: esenol@yildiz.edu.tr \\ ${ }^{2}$ İstanbul Kültür University, Department Of Civil Engineering \\ Bakırköy, Istanbul, Turkey \\ e-mail: adindar@iku.edu.tr \\ ${ }^{3}$ İstanbul Technical University, Department Of Civil Engineering \\ Maslak, Istanbul, Turkey \\ e-mail: ercyuksel@itu.edu.tr \\ ${ }^{4}$ İsik University, Department Of Civil Engineering \\ Şile, Istanbul, Turkey \\ e-mail: faruk.karadogan@isikun.edu.tr
}

Keywords: SAFECLADDING, Energy Dissipation, SAP2000 OAPI, Nonlinear Time-History Analysis, Precast RC Systems, SAMA.

\begin{abstract}
The latest developments in the construction technologies and the materials facilitated the practicing engineers to go higher and energy-efficient buildings. However, the safety of the buildings and the residents has been an issue all the time. This is not an exception for the precast structures. The advantages of the precast elements are the quality assurance and the rapid erection on the site and challenged by the connection details and their performances during the extreme loading cases such as earthquakes. The utilization of a special mechanical connection of the precast members have been in the focus of the recent works in Istanbul Technical University (ITU-STEELAB). The prototypes of the proposed special connectors, called as cushion, were tested in STEELAB in order to determine the mechanical properties such as lateral and axial stiffness and the failure modes. Once the properties were determined, a hypothetical building of single story multi-bay slab type structure was modeled in the computer framework capable of substituting various parametric values into the model, processing and extracting the results for statistical analysis, SAMA. SAMA is developed based on the use of SAP2000 OAPI functions called in MATLAB and Python scripts. In the hypothetical model, the cushions were modeled as link elements and placed between all the precast elements including foundationcladding interface. Extensive non-linear time-history analysis was conducted to identify the damage localization by comparing the energy dissipation at each mechanical connector under ground motion records selected according to focal distance, site conditions and intensity. The preliminary results reveal that the cushions are effectively dissipating a significant amount of energy and mitigating the collapse of the precast elements. The more detailed conclusions will be discussed in the near future.
\end{abstract}




\section{INTRODUCTION}

The current economic conditions demand for minimum cost and shortest period of construction in order to compete in the fierce market. Hence, the precast structures have been the most favorable construction type since the recent developments in the precast member manufacturing and the construction techniques covers the demand of the market. The connection details of the precast members have always been interest of the researchers looking for safer designs against extreme loadings, particularly the seismic loads. The connection of the precast elements (beams, columns, slabs and claddings) should have enough resistance capacity during the ground motions while they must be economical in case of retrofitting after the earthquake. The resistance of the structural members have been defined in terms of strength and deformation, however energy concept, a strong alternative to the current design approaches, can be used in the definition of the seismic resistance.

Kelly et. al. (1972) performed elementary tests on the flat U shaped strip type steel elements, which is presented in Figure 1.6. The relative motion of steel elements is directed parallel between adjacent surfaces, which might be significant energy absorption source by means of rolling, and bending. This study highlighted the significance of steel bent plates, which might be incorporated in structures for absorption of energy generated by earthquake effects.

The energy dissipater type steel members in jointed wall system of two or more precast concrete walls, post-tensioned to the foundation using unbounded tendons, and connected along the vertical joints with special energy dissipating shear connectors were studied in the content of Precast Seismic Structural Systems (PRESSS) program, by Priestley et al, (1991).

A special type of energy dissipative connectors which can be utilized for the all connections mentioned above have been developed in the Structural Dynamics and Earthquake Engineering Laboratory of Istanbul Technical University (ITU-STEELAB) as a part of European FP7 project SAFECLADDING. In this paper, a connector type placed in the precast members' connections was studied to understand the overall response of the one story precast structures subjected to carefully selected and scaled earthquake records [1].

\section{ENERGY DISSIPATING DEVICES AND STRUCTURAL MODELS}

\subsection{ENERGY DISSIPATION DEVICE}

The energy dissipation device used in this study is a deformable steel cushion element that is connected to the RC precast members (slab, beam, column, cladding, foundation) with eccentrically placed single bolts, Fig. 1 . The thickness of the device named as "Cushion" is taken as $8 \mathrm{~mm}$ in the study. 


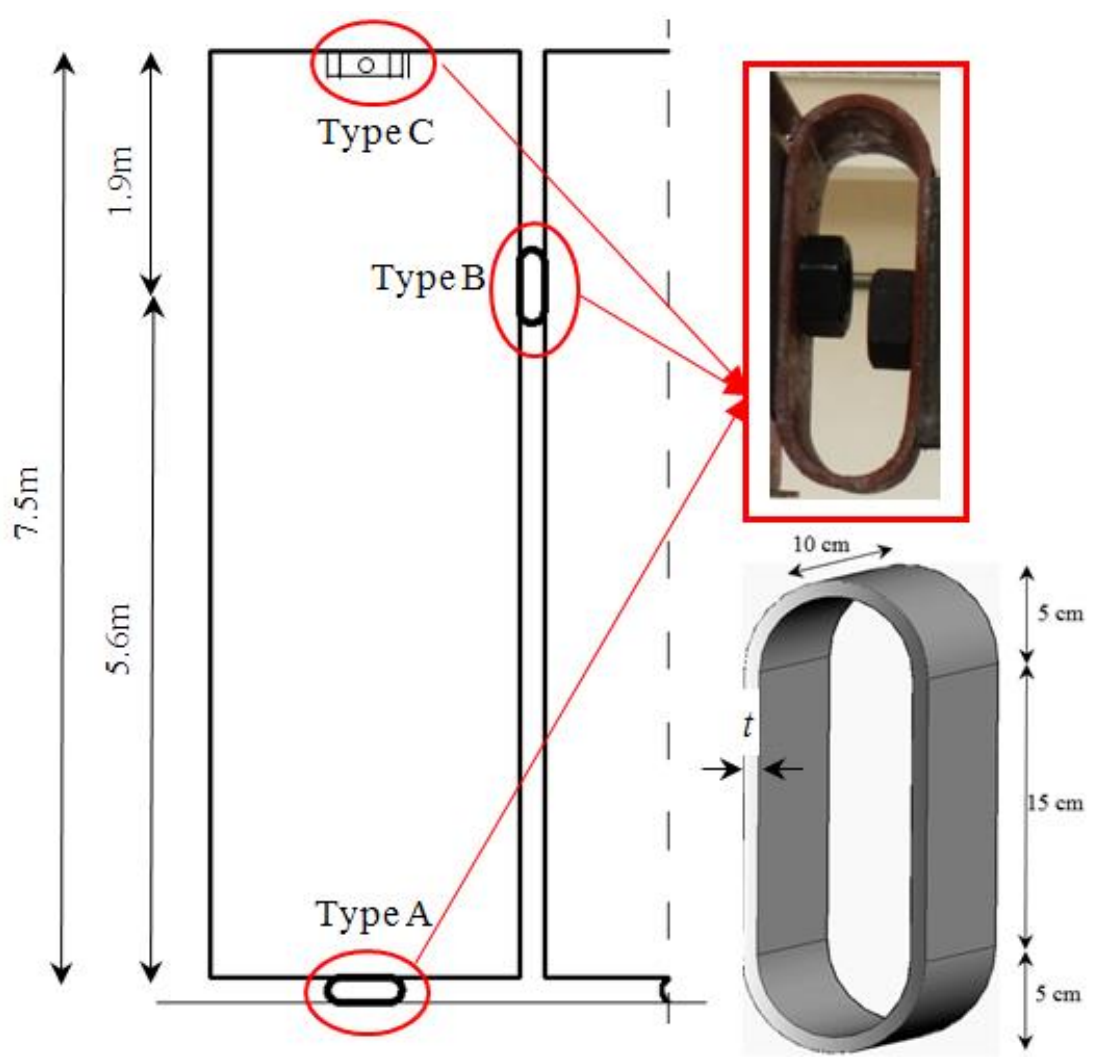

Figure 1: Proposed cushion geometry and their placements between the cladding and the peripheral elements.

The deformation and strength characteristics of the cushion was obtained from the shear tests in ITU laboratories. The displacement based saw teeth test protocol with increasing amplitude up to $20 \mathrm{~cm}$ to both directions, was applied to the cushion. The force-deformation curve measured from the material experiment was carefully studied in the Finite Element Analyses numerical modeling program [2] and two mathematical models, namely WEN 1 and WEN 2, were fit to the experimental data in elastic range and plastic ranges, respectively.

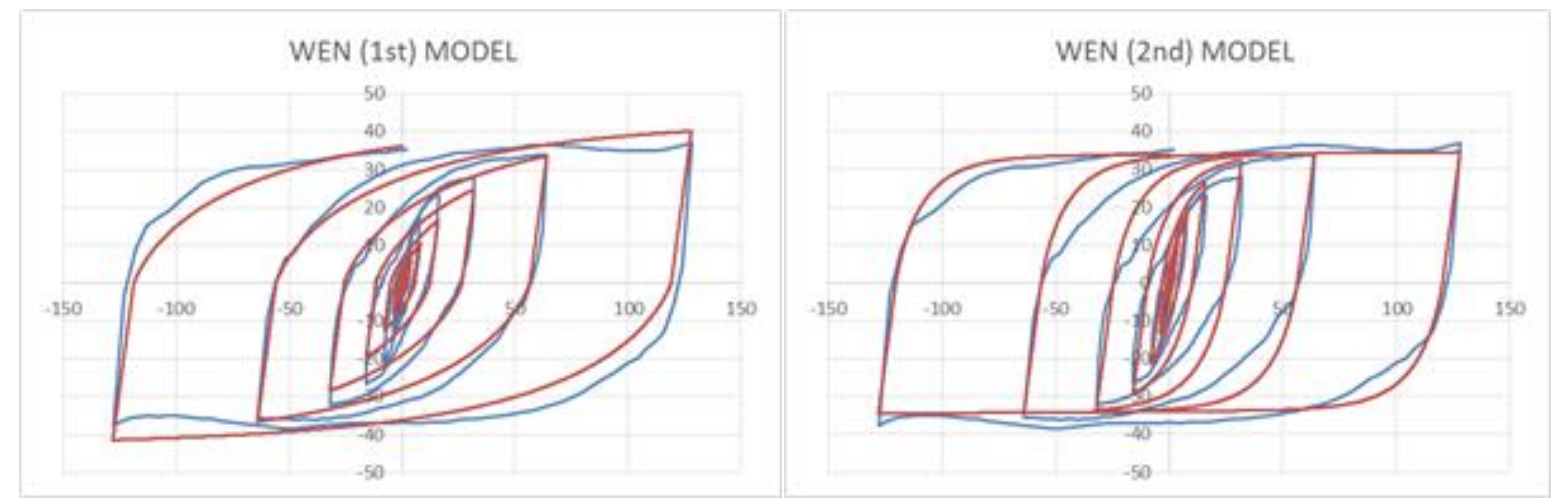

Figure 2: Behavior Models of the cushion.

The fitting success of the all two models were scrutinized in the comparison of the force variation curve on which part of the structural response is achieved, Fig 3. WEN 1 and WEN 2 are in good agreement with experimental data in linear (before \#150) and nonlinear (after \#150) response, respectively. 


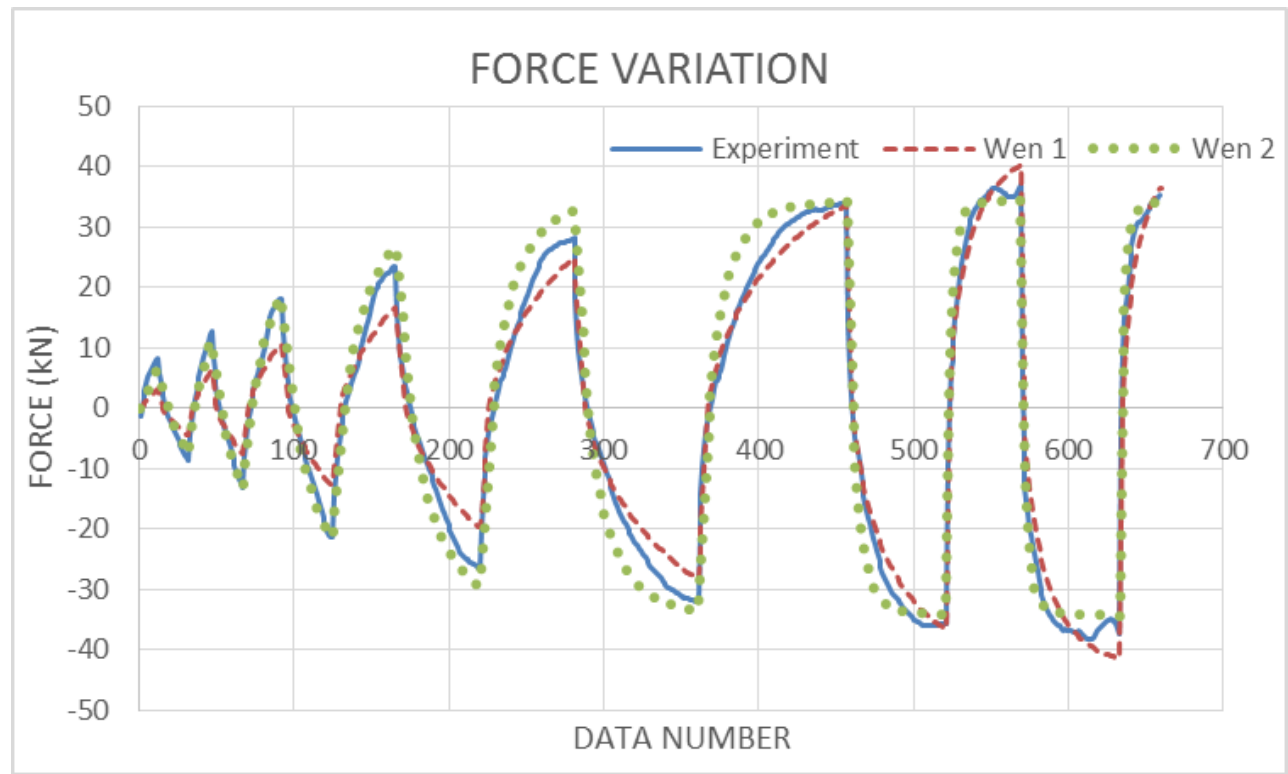

Figure 3: Force variation between experimental and numerical models.

The mechanical parameters computed from the FEM analysis for the cushion element are given in Table 1 and the corresponding force-displacement scheme is depicted in Figure 4.

\begin{tabular}{ccc}
\hline Models/ NL Pros. & WEN 1 & WEN 2 \\
\hline Stiffness (kNm) & 4500 & 4500 \\
Yield F. $(\mathrm{kN})$ & 42 & 34 \\
Stiff. Ratio & 0.001 & 0.001 \\
Yield Exp. & 0.12 & 0.5 \\
\hline
\end{tabular}

Table 1: Parameters for cushion elements

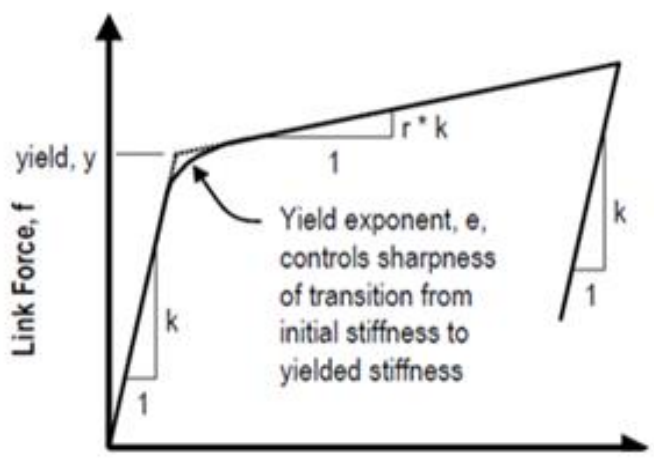

Figure 4.WEN constitutive model based force-displacement relationship.

\subsection{STRUCTURAL MODEL AND CONNECTION VARIATIONS}

The structural model studied is depicted in Figure 5. The features of the structural model is provided as follows;

- The aspect ratio of this slab type building is three; it means that in-plane deformation of slabs will be effective especially on the behavior of middle frame columns even the slabs are cast in situ slabs. It can easily be estimated that the non-rigid connections and in-plane plastic deformations of slabs will pronounce this expectations. 
- There are only two frames running in the long direction and two exterior frames running in transversal short direction. They are consisting of precast columns and beams which may be connected to each other with proposed energy dissipating device. Slab elements and cladding panels are connected to the longitudinal and transversal exterior frames respectively, by means of semi-rigid or rigid connectors.

- Slab elements and cladding panels which are located at the end of building in the short direction, are all connected to each other by steel cushions.

- Cladding panels are connected to the foundation so that this connection will provide both bending hinges and shear dissipations. Those will be parameters of this work.

- Cladding panels are connected to the beams of exterior frames by steel cushions with different strength and rigidities.

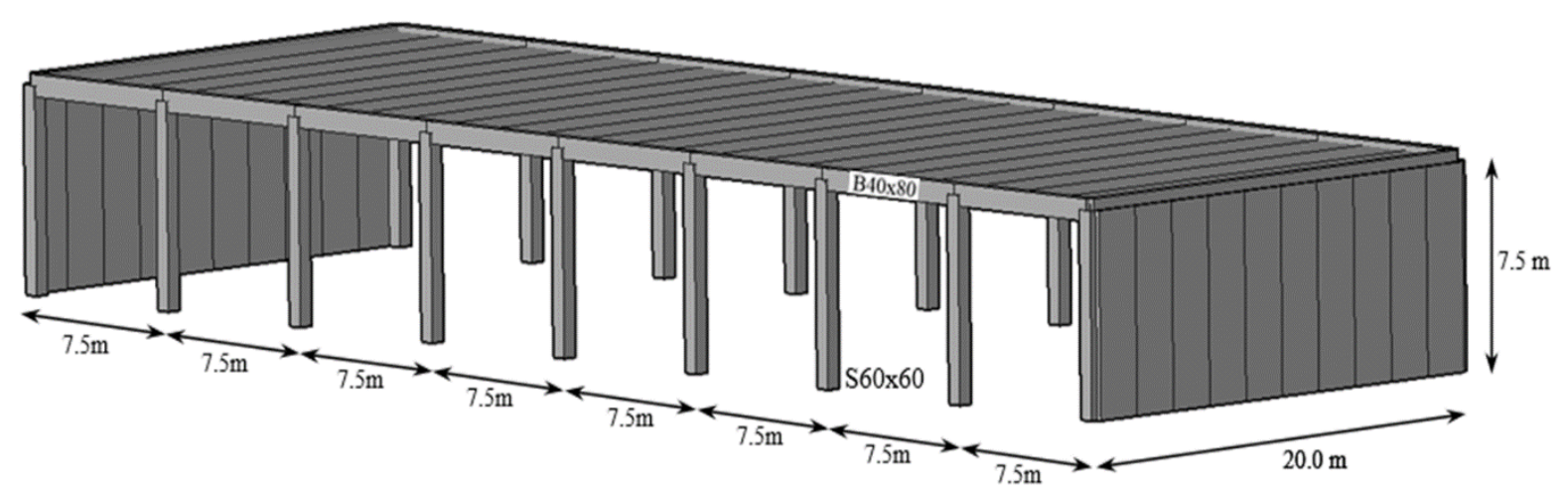

Figure 5. General view of the slab type structure used in the parametric study.

The numerical model constructed in FEM analysis program was taken as the half of the longitudinal direction since the transversal symmetry is provided, Fig. 6 . The connection types between the all precast members (columns, beams, slabs, claddings) and the foundation were also shown in Fig. 6.

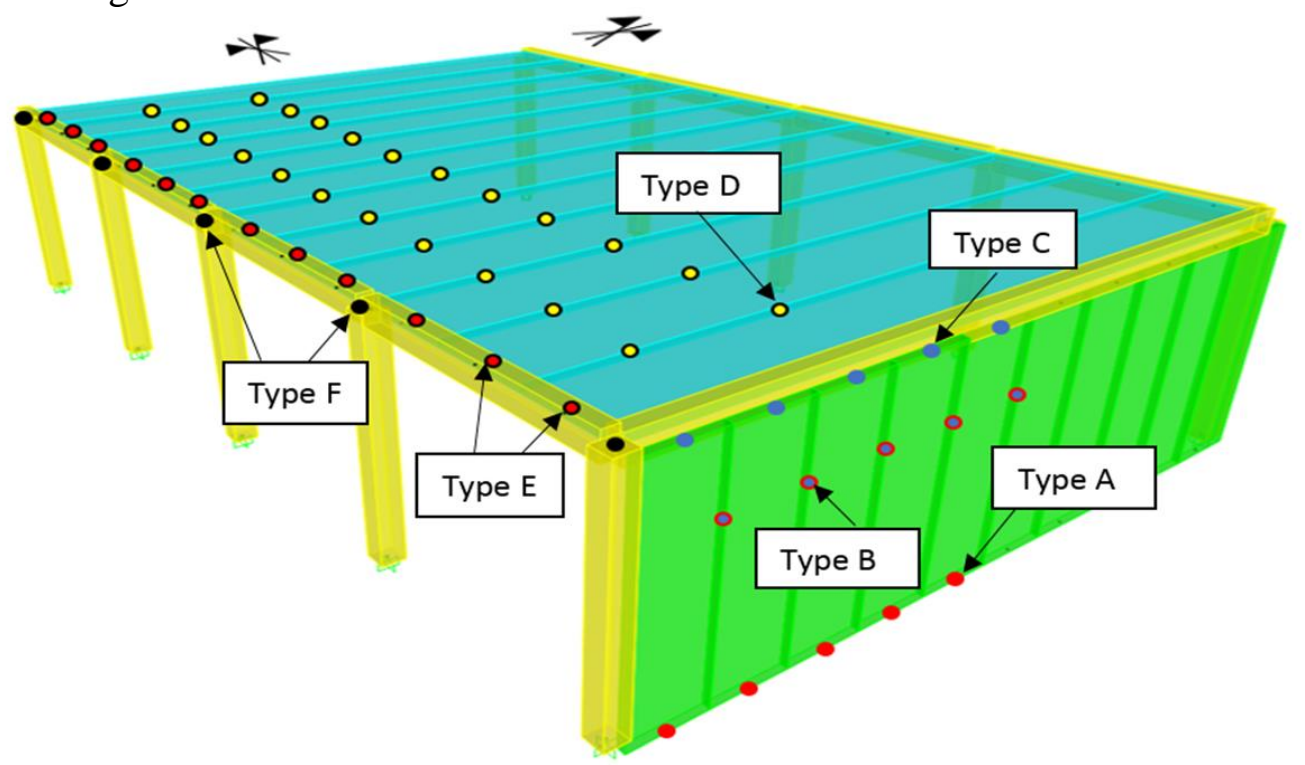

Figure 6. Half of the structural model and designation of connectors. 
To study the energy dissipation characteristics of the entire structural model, the connection types were studied in three different variations. Table 2 displays the connection types and the variations.

\begin{tabular}{ccccccc}
\hline Structural Model & \multicolumn{5}{c}{ Cushion Characteristics } \\
\cline { 2 - 6 } Variation & Type A & Type B & Type C & Type D & Type E & Type F \\
\hline 1 & WEN 1 & WEN 1 & WEN 1 & WEN 1 & WEN 1 & Rigid \\
2 & WEN 2 & WEN 2 & WEN 2 & WEN 2 & WEN 2 & Rigid \\
3 & WEN 2 & WEN 2 & WEN 2 & WEN 2 & Elastic & Rigid \\
\hline
\end{tabular}

Table 2. Connection variations.

The structural variations are organized in order to observe the distribution of the energy dissipation by the connection types and accordingly which part of the structure is susceptible to the damage. Indeed, this approach is the motivation of the FP7 SAFECLADDING project and in this study, we realized how to manage the energy dissipation location which is the key to understand the energy based design. By means of this and further studies, a provision guideline would be recommended in the selection and the installation of the energy dissipation device for the slab-type precast structures with claddings.

\section{GROUND MOTION RECORDS}

The earthquake records used in the study was taken from PEER database [3] with respect to the soil conditions and the distance to the station using a selection and scaling procedure [4].

\begin{tabular}{|c|c|c|c|c|c|c|}
\hline $\begin{array}{l}\text { GM } \\
\text { Set }\end{array}$ & Distance & Soil Condition & $\begin{array}{c}\text { Probability of ex- } \\
\text { ceedance in } 50 \\
\text { years }(\%)\end{array}$ & Analyses Set Name & $\begin{array}{l}\text { No of Rec- } \\
\text { ords }\end{array}$ & $\begin{array}{c}\text { Scaling Factors } \\
\text { Range }\end{array}$ \\
\hline 1 & \multirow{6}{*}{$\begin{array}{c}\text { Far Field } \\
\left(D_{f}>15 \mathrm{~km}\right)\end{array}$} & \multirow{3}{*}{$\begin{array}{c}\text { Firm } \\
(\mathrm{Vs}>700 \mathrm{~m} / \mathrm{s})\end{array}$} & 2 & Farfield_Softsoil_0250 & 16 & $0.94-1.72$ \\
\hline 2 & & & 10 & Farfield_Softsoil_1050 & 16 & $0.91-1.37$ \\
\hline 3 & & & 50 & Farfield_Softsoil_5050 & 15 & $0.82-1.10$ \\
\hline 4 & & \multirow{3}{*}{$\begin{array}{c}\text { Soft } \\
(\mathrm{Vs}<300 \mathrm{~m} / \mathrm{s})\end{array}$} & 2 & Farfield_Firmsoil_0250 & 16 & $0.86-1.56$ \\
\hline 5 & & & 10 & Farfield_Firmsoil_1050 & 16 & $0.61-1.04$ \\
\hline 6 & & & 50 & Farfield_Firmsoil_5050 & 16 & $0.70-1.04$ \\
\hline 7 & \multirow{6}{*}{$\begin{array}{c}\text { Near Field } \\
\left(D_{f}<15 \mathrm{~km}\right)\end{array}$} & \multirow{3}{*}{$\begin{array}{c}\text { Firm } \\
(\mathrm{Vs}>700 \mathrm{~m} / \mathrm{s})\end{array}$} & 2 & Nearfield_Softsoil_0250 & 16 & $0.99-1.76$ \\
\hline 8 & & & 10 & Nearfield_Softsoil_1050 & 17 & $0.80-1.31$ \\
\hline 9 & & & 50 & Nearfield_Softsoil_5050 & 9 & $0.81-1.12$ \\
\hline 10 & & \multirow{3}{*}{$\begin{array}{c}\text { Soft } \\
(\mathrm{Vs}<300 \mathrm{~m} / \mathrm{s})\end{array}$} & 2 & Nearfield_Firmsoil_0250 & 17 & $0.93-1.82$ \\
\hline 11 & & & 10 & Nearfield_Firmsoil_1050 & 18 & $0.58-0.95$ \\
\hline 12 & & & 50 & Nearfield_Firmsoil_5050 & 13 & $0.67-1.09$ \\
\hline
\end{tabular}

Table 3: Properties of the ground motions. 


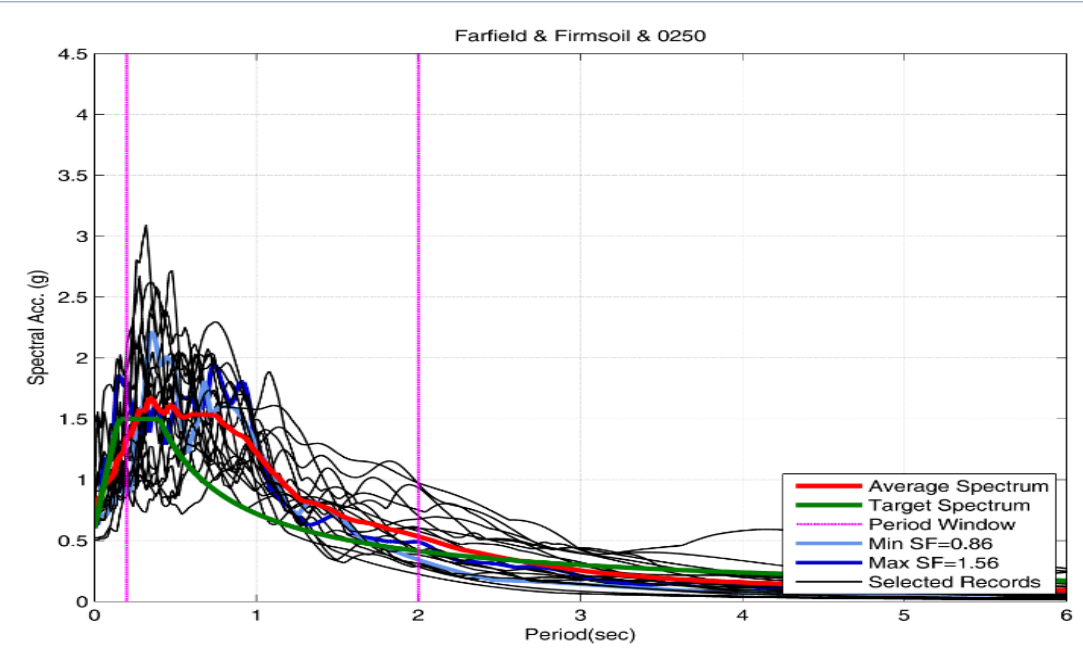

Figure 7: Set of Acceleration Spectrum for Far field-Firm soil 2/50 records.

\section{ENERGY CALCULATIONS AND ANALYSIS ALGORITHM}

The Energy Input $\left(E_{I}\right)$ to the structures energy dissipation $\left(E_{H}\right)$ values of the proposed device were derived from the results of extensive Nonlinear Time History Analysis (NTHA) repeated for each WEN constitutive models. The Energy Input $\left(E_{I}\right)$ values for Single Degree of Freedom Systems is calculated according to Eq. 1.

$$
E_{I}=-m \times \int_{0}^{t} \ddot{u}_{g}(t) d u
$$

where $m$ is the assembled mass at the joint, $\ddot{u}_{g}(t)$ is ground acceleration and $d u$ is the relative displacement of the joint. The total energy imparted into the structure was taken as the summation of the Energy Input values for each joint element. On the other hand, the Energy Dissipation $\left(E_{D}\right)$ values were computed analytically from the closed force-displacement loop area of the cushions modeled in the FEM program.

To overcome the pre- and post-process of the NTHA, the Open Application Protocol Interface (OAPI) commands of the FEM program were employed into a MATLAB based algorithm (SAMA-SAFECLADDING) that runs in High-Power Computing Server in Istanbul Kultur University [5]. SAMA-SAFECLADDING algorithm starts with copying the structural model, adding dynamic nonlinear time history case with parameters such as acceleration data, duration, sampling time, running the analyses cases and finally extracting the response values. Having all the response and the ground motion data, the energy dissipation values were calculated automatically.

The developed MATLAB scripts those employ OAPI commands were used in the civil engineering education for all degrees and also in the research projects. All the steps for NTHA process preparation of the models, running the analyses, extraction of the responses for energy and engineering parameter calculations for each structural variation was less than the expected duration if one has done all the pre- and post-process steps. Considering the amount of the earthquake records of 185 with different length, this analysis period without any additional human involvement is significantly important in the parametric seismic resistance studies. Because, the effort is paid to the evaluation of the results instead of process run.

\section{RESULTS}

The energy imparted into the structures and the energy dissipated by the deforming connectors (cushions) were calculated according to the comprehensive NTHA analyses of three structural model variations having different connection types, Table 2 . The values presented in the 
following results were taken as the arithmetic mean values of all the NTHA for each analyses sets to represent the characteristics of the ground motion records i.e. soil condition, focal distance and seismic intensity.

The first structural model variation was created with all the connectors, except F, of WEN 1 behavior model and the most of the imparted energy dissipated by Type E (connecting slabs to the longitudinal beams), then Type A (connecting cladding to the foundation) and Type B (connecting the claddings) was computed. As seen in Table 4, the remaining connectors of Type $\mathrm{C}$ (connecting the claddings to the transversal beam) and Type $\mathrm{D}$ (connecting the slabs) did not dissipate much energy.

\begin{tabular}{|c|c|c|c|c|c|c|c|}
\hline \multirow[t]{2}{*}{ Analyses Set Name } & \multicolumn{6}{|c|}{ EH/EI ratio (\%) } & \multirow{2}{*}{$\begin{array}{c}\text { ENERGY } \\
\text { INPUT } \\
(\mathrm{kNm}) \\
\end{array}$} \\
\hline & TYPE A & TYPE B & TYPE C & TYPE D & TYPE E & TYPE F & \\
\hline Farfield_Softsoil_0250 & 2.23 & 1.23 & 0.06 & 0.02 & 40.33 & 0.00 & 1275.51 \\
\hline \begin{tabular}{|l|l} 
Farfield_Softsoil_1050 \\
\end{tabular} & 2.12 & 1.33 & 0.06 & 0.02 & 45.92 & 0.00 & 774.51 \\
\hline Farfield_Softsoil_5050 & 1.78 & 1.48 & 0.08 & 0.02 & 60.20 & 0.00 & 156.23 \\
\hline Farfield_Firmsoil_0250 & 2.13 & 1.22 & 0.06 & 0.02 & 43.43 & 0.00 & 1028.47 \\
\hline Farfield_Firmsoil_1050 & 1.97 & 1.45 & 0.07 & 0.02 & 51.42 & 0.00 & 394.82 \\
\hline Farfield_Firmsoil_5050 & 1.79 & 1.56 & 0.08 & 0.02 & 59.49 & 0.00 & 96.13 \\
\hline Nearfield_Softsoil_0250 & 2.50 & 1.23 & 0.05 & 0.03 & 33.72 & 0.00 & 784.76 \\
\hline Nearfield_Softsoil_1050 & 2.43 & 1.35 & 0.06 & 0.02 & 39.69 & 0.00 & 377.20 \\
\hline Nearfield_Softsoil_5050 & 2.14 & 1.24 & 0.07 & 0.02 & 48.82 & 0.00 & 156.27 \\
\hline Nearfield_Firmsoil_0250 & 2.60 & 1.28 & 0.06 & 0.03 & 36.03 & 0.00 & 658.26 \\
\hline Nearfield_Firmsoil_1050 & 2.26 & 1.34 & 0.07 & 0.02 & 48.06 & 0.00 & 200.95 \\
\hline Nearfield_Firmsoil_5050 & 1.99 & 1.27 & 0.07 & 0.02 & 46.54 & 0.00 & 139.78 \\
\hline
\end{tabular}

Table 4. Structural Model variation 1

The second structural model variation was created with all the connectors, except F, of WEN 2 behavior model and the most of the imparted energy dissipated by Type E, then Type B and Type A was computed. Contrary to the Variation 1, the energy dissipation ratios for Type A and $\mathrm{E}$ will decrease whereas Type $\mathrm{B}$ and $\mathrm{C}$ will increase, Table 5. Because, the yielding level of the devices in variation 2 is set to higher than the Variation 1 as seen in Fig. 2.

\begin{tabular}{|c|c|c|c|c|c|c|c|}
\hline \multirow[t]{2}{*}{ Analyses Set Name } & \multicolumn{6}{|c|}{ EH/EI ratio (\%) } & \multirow{2}{*}{$\begin{array}{c}\text { ENERGY } \\
\text { INPUT (kNm) }\end{array}$} \\
\hline & TYPE A & TYPE B & TYPE C & TYPE D & TYPE E & TYPE F & \\
\hline Farfield_Softsoil_0250 & 0.91 & 2.23 & 0.09 & 0.03 & 27.72 & 0.00 & 1283.99 \\
\hline Farfield_Softsoil_1050 & 0.83 & 2.29 & 0.13 & 0.04 & 32.09 & 0.00 & 794.18 \\
\hline Farfield_Softsoil_5050 & 0.62 & 2.67 & 0.22 & 0.04 & 45.31 & 0.00 & 151.80 \\
\hline Farfield_Firmsoil_0250 & 0.81 & 2.22 & 0.10 & 0.03 & 29.62 & 0.00 & 1039.65 \\
\hline Farfield_Firmsoil_1050 & 0.70 & 2.31 & 0.15 & 0.03 & 34.52 & 0.00 & 403.10 \\
\hline Farfield_Firmsoil_5050 & 0.64 & 2.70 & 0.23 & 0.03 & 45.37 & 0.00 & 100.07 \\
\hline Nearfield_Softsoil_0250 & 1.40 & 2.09 & 0.09 & 0.04 & 24.41 & 0.00 & 773.34 \\
\hline Nearfield_Softsoil_1050 & 1.19 & 1.92 & 0.11 & 0.04 & 24.85 & 0.00 & 367.77 \\
\hline Nearfield_Softsoil_5050 & 0.90 & 1.82 & 0.14 & 0.04 & 36.24 & 0.00 & 160.88 \\
\hline Nearfield_Firmsoil_0250 & 1.30 & 1.87 & 0.10 & 0.04 & 23.19 & 0.00 & 653.84 \\
\hline Nearfield_Firmsoil_1050 & 0.94 & 1.91 & 0.14 & 0.04 & 32.38 & 0.00 & 191.03 \\
\hline Nearfield_Firmsoil_5050 & 0.93 & 2.11 & 0.16 & 0.04 & 36.06 & 0.00 & 137.42 \\
\hline
\end{tabular}

Table 5: Structural Model variation 2.

The third structural model variation was created with all the connectors, except E and F, of WEN 2 behavior model and so that the most of the imparted energy dissipated by Type B, then 
Type A and Type $\mathrm{C}$ was computed. Keeping the Type E respond elastic by increasing the yield level, the energy dissipation of the structure has reoriented towards the connectors around the claddings, Type A, B and C.

\begin{tabular}{|c|c|c|c|c|c|c|c|}
\hline \multirow[t]{2}{*}{ Analyses Set Name } & \multicolumn{6}{|c|}{ EH/EI ratio (\%) } & \multirow{2}{*}{$\begin{array}{l}\text { ENERGY } \\
\text { INPUT }(\mathrm{kNm})\end{array}$} \\
\hline & TYPE A & TYPE B & TYPE C & TYPE D & \begin{tabular}{|l|} 
TYPE E \\
\end{tabular} & TYPE F & \\
\hline Farfield_Softsoil_0250 & 0.95 & 3.63 & 0.13 & 0.05 & \begin{tabular}{|l|}
0.00 \\
\end{tabular} & 0.00 & 1323.79 \\
\hline Farfield_Softsoil_1050 & 0.95 & 3.93 & 0.20 & 0.05 & 0.00 & 0.00 & 820.71 \\
\hline Farfield_Softsoil_5050 & 0.89 & 6.08 & 0.48 & 0.06 & 0.01 & 0.00 & 153.21 \\
\hline Farfield_Firmsoil_0250 & 0.88 & 3.69 & 0.15 & 0.05 & 0.00 & 0.00 & 1070.36 \\
\hline Farfield_Firmsoil_1050 & 0.88 & 4.05 & 0.25 & 0.05 & 0.00 & 0.00 & 411.37 \\
\hline Farfield_Firmsoil_5050 & 0.89 & 6.36 & 0.54 & 0.06 & 0.01 & 0.00 & 106.12 \\
\hline Nearfield_Softsoil_0250 & 1.52 & 3.53 & 0.16 & 0.06 & 0.00 & 0.00 & 785.10 \\
\hline Nearfield_Softsoil_1050 & 1.38 & 3.07 & 0.17 & 0.05 & 0.00 & 0.00 & 363.01 \\
\hline Nearfield_Softsoil_5050 & 1.12 & 3.58 & 0.27 & 0.06 & 0.00 & 0.00 & 158.99 \\
\hline Nearfield_Firmsoil_0250 & 1.43 & 3.01 & 0.15 & 0.05 & 0.00 & 0.00 & 661.74 \\
\hline Nearfield_Firmsoil_1050 & 1.21 & 3.37 & 0.23 & 0.05 & 0.00 & 0.00 & 185.33 \\
\hline Nearfield_Firmsoil_5050 & 1.15 & 4.45 & 0.34 & 0.06 & 0.00 & 0.00 & 134.20 \\
\hline
\end{tabular}

Table 6: Structural Model variation 3.

Noticing the Energy Input (EI) values for all structural variations it is clear that inelastic response characteristic of the devices do not significantly affect energy imparted into the structure. However, distribution of the energy dissipation within the structure is absolutely sensitive to cushion response characteristics.

\section{CONCLUSIONS}

The summary of the study is given in the following;

- One of the cushions studied in SAFECLADDING project, $8 \mathrm{~mm}$ hollow cushion, was used in the analyses. The shear behavior of the cushion was determined from Material Tests.

- The numerical models of the cushion were defined by using a FEM analysis program. Two different behavior model based on WEN Model. The first model (WEN 1) fits the plastic region of the experimental hysteresis while the second (WEN2) is more consistent in the elastic region.

- Three variation of the structural model which has been used as benchmark case in SAFECLADDING project was studied with different connector types.

- Sets of ground motion records selected and scaled as the test data in SAFECLADDING were used in the Nonlinear Time History Analyses of the each structural variation.

- In total, 185 NTHA for each variation was conducted using a computer algorithm "SAMA-SAFECLADDING" that provides efficiency in the pre- and post-process. SAMA-SAFECLADDING algorithm was developed in MATLAB program using OAPI commands.

- The results of the NTHA were used in the computation of the Energy terms of Input (EI) and Plastic (ED).

According to the results of the study, the conclusions are listed as following;

- Energy dissipation within the structure is partly provided by the devices those can be plastically deformed. The deformation characteristic of these devices are related to the geometric and mechanical properties. Therefore, the behavior numerical model defined to the device influences the energy dissipation characteristics of the entire structure. As observed between the Structural Variation models 1 and 2, the increase in the yielding 
level of the cushion ( $8 \mathrm{~mm}$ hollow) significantly affects the energy dissipation values of the devices, therefore, higher the yield level results in lower energy dissipation which consequently affect the selection of the device properties.

- On the other hand, the change of the connector's response in one location, here it was the Type E in Structural Variation 3, resulted the reorientation of the energy dissipation values of the cushions. Therefore, it may be possible to control the energy dissipation distribution within the structure if the connectors' energy dissipation and deformation characteristics are predictable. The structural variation 3 clearly reveals the redistribution of the energy dissipation between the different connector locations.

- Comparing the results of the structural variations, the slabs freedom is more provided in the following order variation 1, 2 and 3. Larger drift of the mass is requires higher energy dissipation. Therefore, Type E connector should be taken as criterion in the evaluation of the behavior model for economical and safer design of the slab type structures. WEN 2 behavior model revealed that less amount of energy was dissipated by the cushions. Based on this fact, using WEN 2 model for the 8mm hollow cushions can be recommended for design.

The motivation of the FP7 SAFECLADDING project and also this study is to understand the influence of the cushion characteristic and location on energy dissipation of the structure. Having studied this influence on several numerical models it is highly possible to lead an energy based seismic resistance and design of the slab type precast structures.

In the future studies, the other cushions tested in SAFECLADDING will be included into the structural model variations in order to propose a guideline for optimized the energy distribution in slab type precast buildings.

\section{REFERENCES}

[1] SAFECLADDING EU Project - Improved Fastening Systems of Cladding Panels for Precast Buildings in Seismic Zones, 2012-2015

[2] SAP2000 v16.0, Computers \& Structures Inc., Berkeley, CA, USA

[3] PEER Strong Ground Motion Database, Pacific Earthquake Engineering Research Center, California, http://ngawest2.berkeley.edu/

[4] Bal, I. E. et al., "An engineering approach for structural-oriented earthquake record selection", Second European Conference on Earthquake Engineering and Seismology, Istanbul, Turkey, August 24-29, 2014.

[5] Dindar, A.A, Önen, Y.H. and Tugan, B., A cloud computer applicaton in civil engineering education and research: SAMA, In the proceedings of 11th Advances in Civil Engineering, 21-25 October, Istanbul, Turkey. 2014

[6] Priestley, M. J. N. Overview of PRESSS Research Program. Journal of Precast Concrete Institute. Vol. 36, no. 4, pp. 50-57, 1991

[7] Kelly, J. M., Skinner, R. I., and Heine, A. J., Mechanisms of Energy Absorption in Special Devices for use in Earthquake Resistant Structures. Bulletin of the New Zealand Society for Earthquake Engineering. Vol. 5, no. 3, pp. 63-73, 1972 
[8] Khajehdehi A., Güllü A., Gökçe T., Özkaynak H., Yüksel E., Karadoğan F., Cyclic test of the precast panels equipped with steel cushions. Poster Presentation in Second European Conference on Earthquake Engineering and Seismology, Istanbul, Turkey, August 25-29, 2014

[9] MATLAB Release 2014b, The MathWorks, Inc., Natick, Massachusetts, United States. 